E centenario del nacimiento de Brecht fue una escusa como otra cualquiera para traducir y editar por primera vez en español "La caida del egoista Johann Fazzer" de Bertolt Brecht, versión escénica de Heiner Müller.

Berlolt Brecht, nacido en 1998 en Augsburgo /Alemania, comienza a trabajar en La caida del egoista Johann Fatzer en Berlin al final del año 1926. El material reunido por Brecht bajo este titulo durante años posteriores abarca varios centenares de páginas pero, aunque trabajó intensamente durante muchas épocas en este texto, la obra quedó inacabada.
No puedo dejar de manifestar mi admiración por Brecht, lamentando el destierro a que están sometidos sus textos. La lectura de sus obras sigue contagiada del idealismo politico a que fue sometida por la utopia de los años sesenta. Y, sin embargo, Brecht fue un idealista/cinico o un cinicolidealista que reflexionó sobre su contemporaneidad destruyendo casi cualquier ortodoxia que limitara al hombre. Brecht estambiénel profeta de los desheredados, de los que de una u otraforma son manipulados por la sociedad que los utiliza, y eso perdura, sigue vigente, le trasciende; es cierto que en situaciones no exactamente iguales pero si establece parábolas que pueden y deben servir para el espectador contemporáneo, porque:

\title{
LA CAÍDA DE BERTOLT BRECHT VISTA POR JOHANN FATZER
}

Heiner Müller (1929-1995) elabora una versión escénica de Fatzeren 1978 para una representación dirigida porWolfgang Karge I Matthias Langhoff en el "Deutsches Schauspielhaus" de Hamburgo. La falta de recepción de públicoy critica que obtuvo la propuesta de Karge/ Langhoff, fue corregida posteriormente con su apoteósico estreno en el Berliner Ensemble, dirigida por el propio Müller; y esta versión es la que hemos traducido al español por encargo de la Diputación de Sevilla en el marco del "Homenaje a Bertold Brecht".

Es frecuente oir en determinados cenáculos las frases: "Brecht ha perdido actualidad", "Brecht ya no está de moda", "es excesivamente coyuntural" y cuando nos propusieron la traducción también en nosotros surgió la duda sobre la eficacia de un texto centrado en el análisis de una situación europea concreta: $1^{\mathrm{a}}$ guerra mundial, intentos de creación de soviets en la propia Alemania, inicios de la República de Weimar y primera etapa de creación de la URSS. Y la duda era lógica porque iqueda algo de todo aqueIlo?, pareceria que después de la caida del muro, seguir hablando de la época de creación de los soviets y su posterior desarrollo era algo muy lejano y desde luego fuera de la posmoderna moda de ignorar el pasado. Habia, no obstante, algo que nos atraia desde la precipitada primera lectura que nos hizo volver a leerlaantes de aceptar el encargo. Estos fragmentos estaban cargados del mejor Brecht, su sardónica visión sobre la sexualidad nos permitiaalejarnos de los encasillamientos politicos a que normalmente está sometido, su irónica y nada ortodoxa posición sobre determinados conceptos leninistas rompen el estereotipo que con frecuencia nos venden. $Y$ a todo ello unida la provocadora y parlicular visión de Heiner Müller relacionando determinados comportamientos de situaciones y personajes con la del grupo Baader/Meinhof.

\author{
Pedro Álvarez-Ossorio \\ Director de Teatro
}

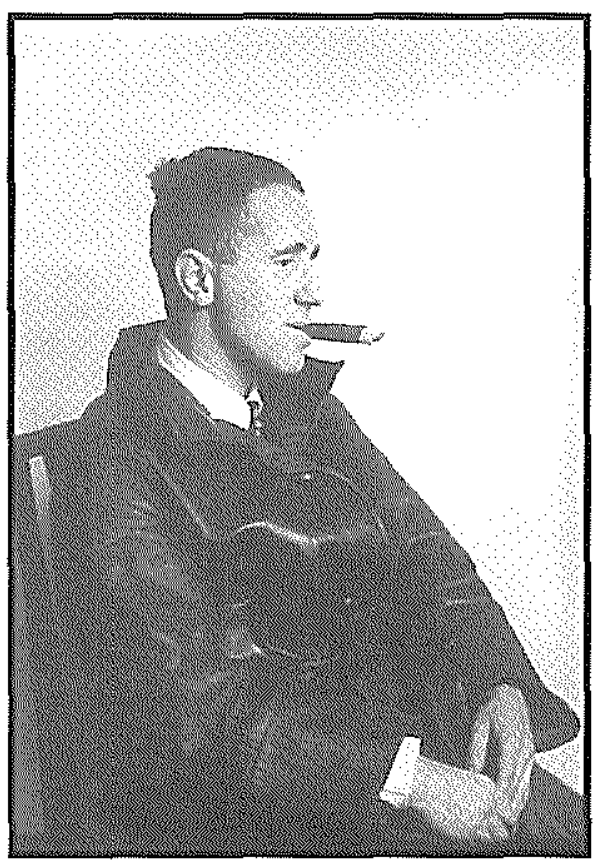


66 Elenden von heute

Sind morgen glücklich; was tut's wenn sie Heute noch sterblich sind?

Wir raten euch: seht

Euch an diese vier, denn ihr werdet sie

Untergehend sehn handeln wie

Aufwärtsgehende. soviel besorgt

Nicht sterbend, der ohne Erben ist,

So genau prüft seines hauses jeglichen Stein nicht

Beim Bau, wer nie drin zu wohnen denkt

[...]

Drum höıt zu

Denn viel wichtiger für euch

Ist, was sie sagen, als

Für sie selber."
66 os miserables de hoy

Mañana serán felices. ¿Qué importa

Si aún hoy son mortales?.

Os aconsejamos: mirad

A esos cuatro, vais a verlos

Hundirse, actuando

Como si ascendieran. No les preocupa

Su muerte. Quien no tiene herederos

No examina tan detenidamente las piedras de su casa

Cuando construye, como quién no piensa vivir en ella."

[.....]

"Por eso escuchad atentamente

Es más importante para vosotros

Lo que dicen

Que para ellos mismos."

Si añadimos que el texto es, sobre todo, un claro manifiesto antimilitarista que podria aplicarse a tantos conflictos bélicos que nos son tan cercanos, deberiamos concluir que es de un enorme interés y vigencia el debate dramático creado. Participamos, con unos personajes en situación critica, sobre èl o los modelos de sociedad a establecer, y puede ayudarnos a reflexionar, al menos sobre las limitaciones del llamado pensamiento único.

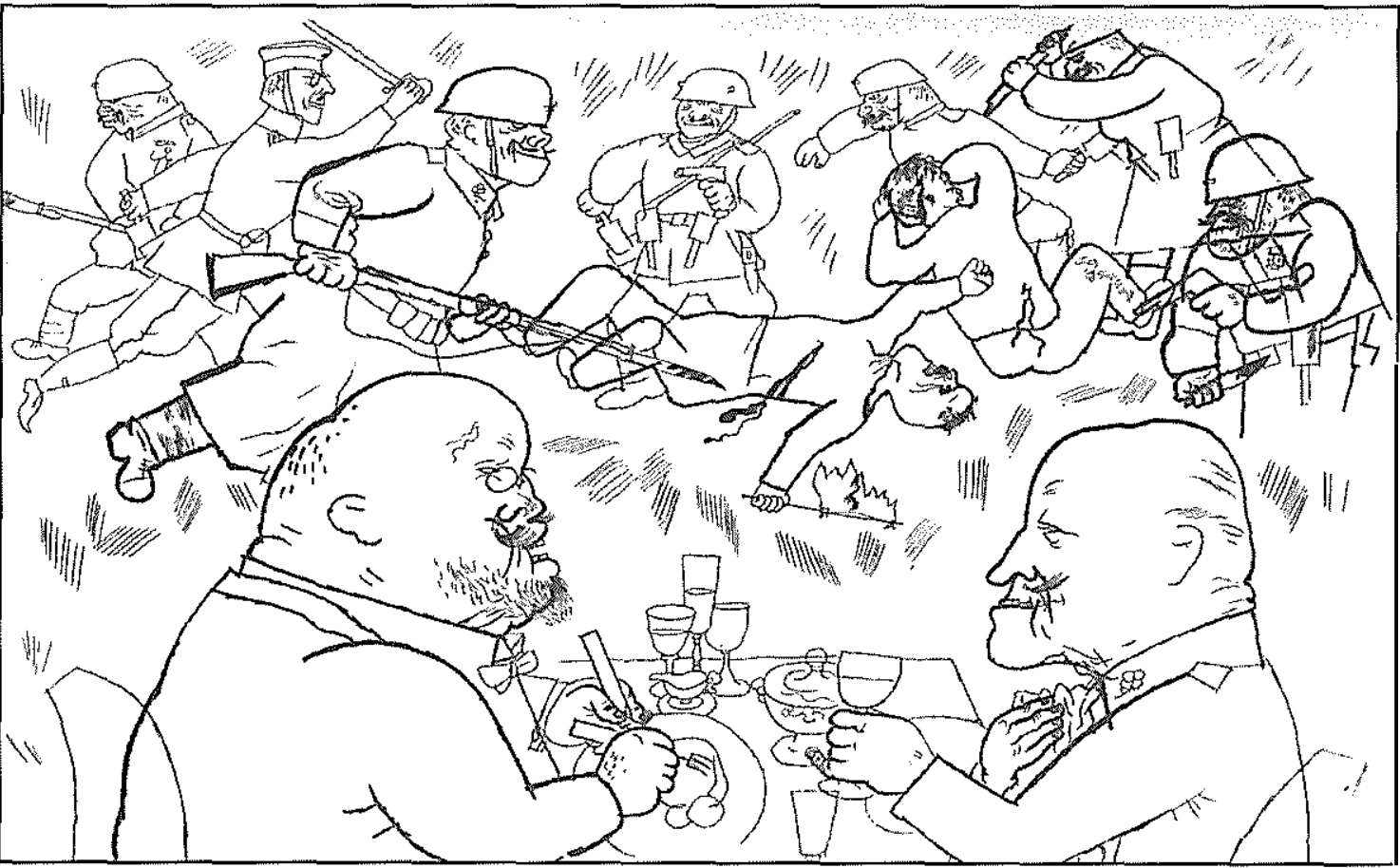

Litografia de Geroge Grosz, 
Un texto, por otra parte, de alto valor poético comparable al mejor Hölderlin. Hemos mantenido la estructura en versos libres de la propuesta de Brecht con mayúsculas en los encabezamientos y anulando las comas de los finales de versos, que favorecen el encabalgamiento configurando un ritmo en el decir $y_{1}$ a veces, unas pausas versales que provocan un doble sentido con la continuidad de la frase. La frase partida también viene a realzar los contenidos de los finales de versos y los fragmentos sueltos del siguiente.

Asimismo, hemos intentado mantener los múltiples niveles de lenguajes de la obra original, donde los términos coloquiales se alternan con otros más cultos y otros que recuerdan las traducciones de la biblia y términos de la liturgia cristiana. La habilidad de Brecht para mostrar en sus textos las contradicciones de los personajes por medio del lenguaje no podia ser eludida; de ahi que las aparentes incoherencias se conviertan en pautas de reflexión por el distanciamiento que producen para el espectador.

Por último, la deconstrucción/construcción de los fragmentos realizada por Müller en esta propuesta escénica, enriquecen y amplian aún más ese juego de tensiones contradictorias que al mismo tiempo son tan desveladoras de su pensamiento y ofrecen unas nuevas perspectivas de futuro de la caida de Bertolt Brecht.
¿De qué futuro? ¿De què Brecht?

Del dramaturgo

Del Director de puesta en escena

Del poeta

Del teórico

Del que quieren los ortodoxos

Del idealista o del cínico.

Del Brecht de la empatia

Del Brecht de la distancia

¿Del idealista/cinico?

¿Del cinicolidealista?

Reflexionando sobre la contemporaneidad

Destruyó casi cualquier ortodoxia.

¿Un teatro de la emoción?

¿Un teatro de la significación?

$\mathrm{Ni}$ adivino ni futurólogo

Busco

Y Fatzer-Brecht contesta: ch weiss nicht, ob ich mein Stück heraussschnitt

Wies alle Welt tut, aber ich darf's nicht

Da muss ich acht geben, dass ich nicht in ihre Tretmühl

Hereinkomme, nur weil

Ich nicht darf und sie mahlt

Entkörntes Stroh.

Dies Fleisch ist faul und nicht mehr

Lohnt sichs für einen Mann

Wie mich, etwas zu übernehmen, was

Heute faul und morgen unbekannt.

Doch bin ich geboren mit Hang zum Nehmen

In aller Welt. o sé si soy carne de cañón

Como todo el mundo, aunque no debiera

Tengo que tener cuidado para no caer

Bajo la rueda de molino, porque yo

No debo y ella tritura

La paja sin granos.

La carne está podrida y

No vale la pena que un hombre

Como yo, cargue con algo que

Hoy está podrido y el mañana es incierto.

Desde que naci tiendo a recibir

Por todas partes. 
$D^{\text {nasiom }}$

In einem Buch gelesen:

Die stärksten und bösesten Geister haben bis jetzt die Menschheit am meisten vorwätts gebracht: sie entzündeten immer wieder die einschlafenden Leidenschaften - alle geordnete Gesellschaft schläferi die Leidenschaften ein - sie weckten immer wieder den Sinn der Vergleichung, des Widerspruchs, der Lust am Neuen, Gewagten, Unerprobten, sie zwangen die Menschen, Meinungen gegen Meinungen, Musterbilder gegen Musterbilder zu stellen. Mit den Waffen, mit Umsturz der Grenzsteine durch Verletzung der Pietäten zumeist: aber auch durch neue Religionen und Moralen! Dieselbe Bosheit ist in jedem Lehrer und Prediger des NEUEN, welche einen Eroberer verrufen macht, - wenn sie auch sich feiner äussert, nicht sogleich die Muskeln in Bewegung setzt und eben deshalb auch nicht verrufen macht. Das Neue ist aber unter allen Umständen das BÖSE, als das, was erobern, die alten Grenzsteine und die alten Pietäten umwerfen will; und nur das Alte ist das Gute! Die guten Menschen jeder Zeit sind die, welche die alten Gedanken in die Tiefe graben und mit ihnen Frucht tragen, die Ackerbauern des Geistes. Aber jedes Land wird endlich ausgenützt und immer wieder muss die Pflugschar des Bösen kommen.

Bind mir den Strick auf!

$[\ldots]$

Und er ergreitt ihre Brust unterm Hemd, die liebliche

Seine grobe Hand überredet sie, sorgt, dass sie

Aufsteht und hart wird, und er ergreift

Sorgsam ihr Hinterteil und wiegt es

Freudig und merkt, dass die

Enggepressten Schenkel sich öffnen und

Ihre Hand ihn zu sich zieht, und das Spiel so sehr alt

Erneuert sich und auch

die beliebte Bewegung.
$L^{\text {olei }}$

En un libro:

Han sido hasta ahora los espiritus más fuertes y malignos los que más han empujado al progreso de la humanidad: encendiendo, siempre de nuevo, pasiones adormiladas - todas las sociedades ordenadas adormecen las pasiones - despertando constantemente las ganas de comparar y contradecir el gusto porlo nuevo, 10 atrevido, 10 inexperimentado y obligando a los hombres a confrontar opinión contra opinión, ejemplaridad contra ejemplaridad; usando armas, revolucionando fronteras y, casi siempre, dañando viejas piedades, pero siempre ;con nuevas ideas religiosas y morales! Todos Ios predicadores y maestros de lo NUEVO tienen la misma malicia, origen también de la difamación de los conquistadores - aunque lo hagan elegantemente sin poner en funcionamiento la musculatura y no parezca tan difamatorio. Lo nuevo es, bajo toda circunstancia, 10 MALO, el que quiere conquistar algo, cambiar viejas fronteras o derribar viejas piedades; $y$ ¡sólo lo viejo es I o bueno! Los buenos hombres de todos Ios tiempos profundizan en las antiguas ideas y sacan frutos de ellas, son los cultivadores del espiritu. Pero cada tierra acabará por agotarse y siempre volverá el arado del mal.

Suéltame la cuerda.

[...]

Yélle toca el pecho bajo la blusa; el cariño

De su ruda mano logra persuadirla

Levantando y endureciendo su pecho. Y agarra

Su trasero moviéndolo

Alegremente y nota que los

Apretados muslos se abren y

Su mano tira de èl hacia ella, y el viejo juego

Se reanuda y pasan con èl

Al ansiado movimiento.

l...l

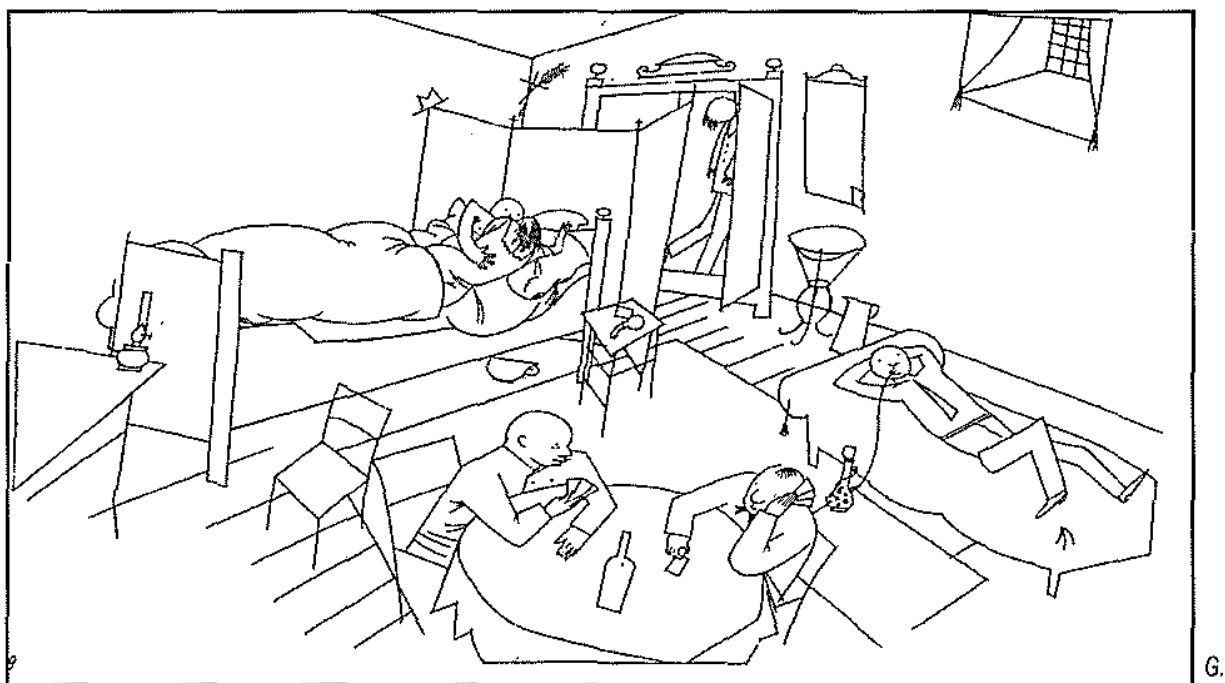


CHOR

U

richtig handeln, die dem Lernenden das Geschlechtliche als natürlich hinstellen, als sauber, harmlos und verständlich. Recht aber haben, die es ihm als unnatürlich beweisen, also als schmutzig, gefährlich und unverständlich. Jeder weiss, dass bei allen Tieren das Geschlechtliche nicht natürlich ist, denn sie leben ihre längste Zeit wie ohne Geschlecht. Aber nicht um den Lemenden von der Liebe abzuhalten, soll man ihm die Liebe so schmutzig oder unnatürlich schildem, sondem allein, um ihm die Wahrheit zu sagen. Nicht um ihm Abscheu zu erregen, sondern um ihn Schrecken zu lehren. Drum ist die beste Art, ihn die geschlechtliche Liebe zu lehren, so, wie es die Knaben unter sich machen: sie reden lachend und erhitzt vom Geschlechtlichen und zeichnen grosse und schmutzige Symbole auf die Wände der Häuser, die jenen gleichen, die von den Religionen der weisesten Rassen benützt werden. Und auch dadurch ist diese Art der Belehrung gut, weil sie unter solchen vor sich geht, die sich nicht nur mit Worten, sondern auch mit Händen berühren können. Warum aber ist das Geschlechtliche unnatürlich? Viele sagen, dass es wohl grauenhaft sei, Leben zu erzeugen, und nur durch eine schlimme Lust werde der Mensch verlockt, solches zu begehen. Dies scheint zu beweisen die Trauer nach dem Beischlaf, die allen Tieren gemeinsam ist. Auch sind die Zeichnungen des Weibes beim Beischlaf so, als wäre es krank, denn wenn dieses Krankhafte auch Lust erzeugt, so ist es deswegen doch krank.

\section{CHOR}

Zerstörung des Zimmers

\section{Der Zeit.}

Das Ganze, da ja unmöglich

Einfach zerschmeissen

Für Experiment - ohne Realität

Zur Verselbständigung

Alles, was heute gedacht wird, ist

Nur, damit gut erscheine, was alles gemacht

wird! Alles, was heute gemacht wird, ist falsch, also ist alles,

was

Heute gedacht

Wird, falsch

der Zweck, wofür eine arbeit gemacht wird, ist nicht mit jenem

Zweck

Identisch, zu dem sie verwertet wird

Die Erkenntnis kann an einem anderen Ort gebraucht

Werden, als wo sie gefunden wurde.
CORO

Stán en un error los que enseñan a los alumnos lo sexual como algo natural, limpio, inocente y comprensible. Tienen razón los que lo presentan como contra natura, sucio, peligroso e incomprensible. Todos saben que para los animales 10 sexual no es su estado natural, puesto que la mayor parte del tiempo viven sin sexo. Pero no es para alejar a los alumnos del amor por lo que debemos describirselo como sucio o antinatural, sino para decirles la verdad. No para producirles repulsión, sino para enseñarles el terror. Es el mejor modo de enseñar el amor sexual, coincide con lo que hacen los muchachos cuando hablan del sexo, riendo y acalorándose, pintando simbolos grandes y sucios en las paredes de las casas, parecidos a los de las más sabias religiones de las razas humanas. Este tipo de enseñanza es bueno porque se realiza no sólo con palabras, sino con manos que se tocan. ¿Por qué lo sexual es poco natural? Muchos dicen que es horroroso engendrar vida y sólo un apetito maligno induce al hombre a desearlo. Parece que la tristeza poscoito, que sienten todos los animales, lo confirma, como los movimientos de la mujer durante el coito, bruscos e incontrolados, como si estuviera enferma. Aunque este estado enfermizo produzca placer, no por ello es menos enfermizo.

\section{CORO}

Destrucción de la habitación

Del tiempo

El todo, que no es posible

Destruir

Como experimento - sin realidad

Para la autocomprensión

Todo lo que se piensa hoy

Hoy únicamente sive para justificar lo que se hace

Todo lo que se hace es falso, por lo que, todo lo que

Se piensa hoy

Es falso

El fin del trabajo no es idéntico

A cualquier fin para el que pueda ser usado

El conocimiento puede ser utilizado

En distinto ámbito al que fue encontrado. 


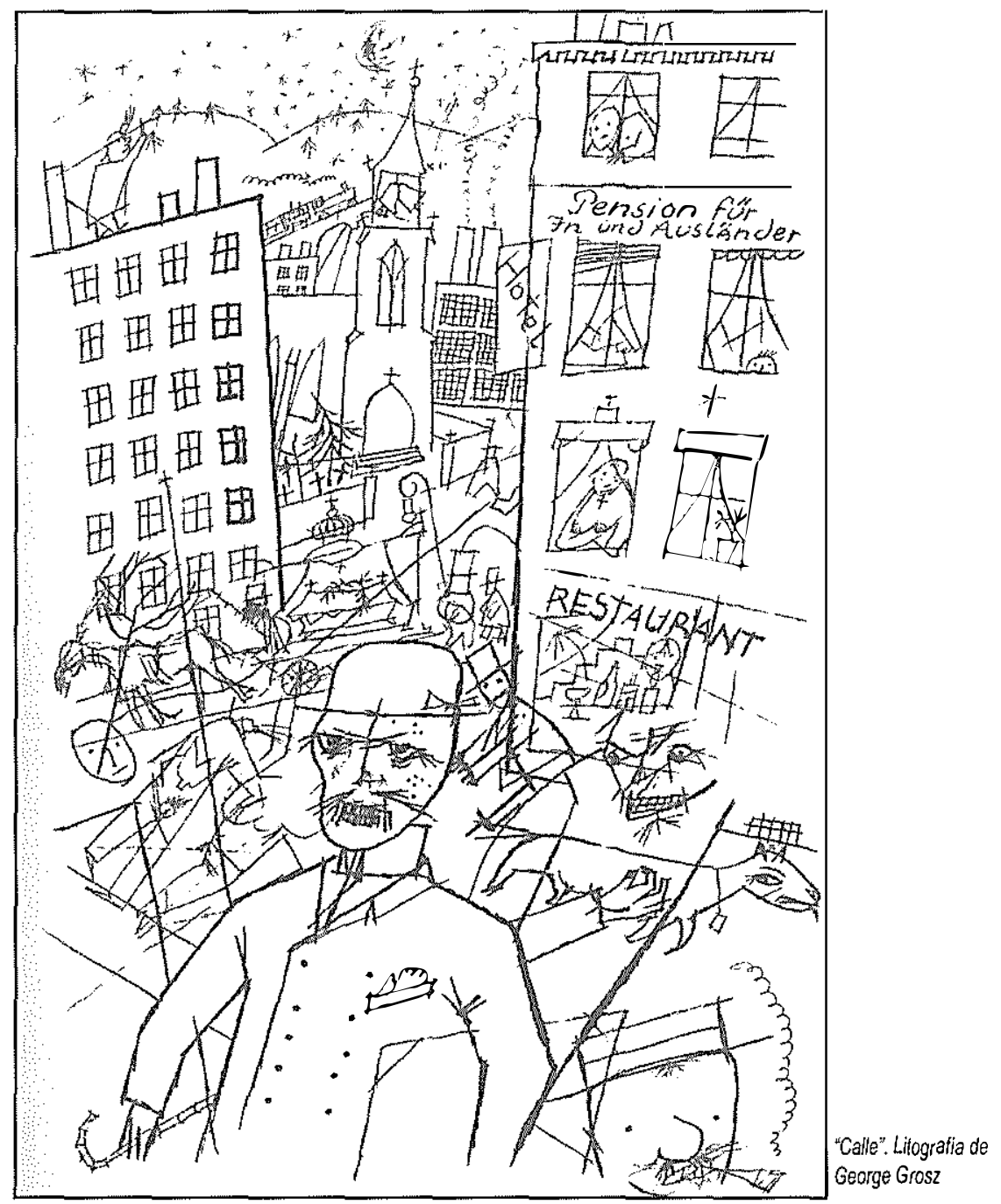

\section{KAUMANN}

Hast du

Geschlachtet, Fatzer?

FATZER (lacht)

Kann sein: einen Fleischer.

Das Morgenrot

Ist sehr schön und der Mensch

Hat ein Herz und es ist

Kühn, eins zu haben.

Jung ist freilich

Besser als alt.

Was vorbei natürlich

Ist nicht besser als

Was kommt

Und nicht so

\section{KAUMANN}

¿Has

matado, Fatzer?

FATZER (se rie):

Pudiera ser: un carnicero.

El rojo amanecer

Es bello y el hombre

Tiene corazón y

Orgullo de tenerlo.

Ser joven es naturalmente

Mejor que ser viejo.

Lo pasado, por cierto

No es mejor

Que lo que ha de venir

Ni tan distinto 
Verschieden ist die

Schlachtluft voll Feuer und Rauch Von einem Sommertag

Als dieser Fatzer von jenem ist

Also sind die Situationen

Die Mütter der Menschen.

Es gibt auch andres, andere Wege Aber ich

Rat euch nicht, sie zu beschreiten.

Ganz unbeurteilbar

Ist der Mensch dem Menschen

So wie gegangen durch

Ungeheuren Magen

Der jeden Knochen und haut durch Saft einschmilzt

So dass du aus dem Kot nicht

Fisch noch Apfel auskennst

So liegtim trüben Brei das Menschenleben

Ist es genossen vor dem Aug der Welt

nach was er grif, den gierigen

Mund zu stillen

Gegangen ists aus Luft und Wasser und Nicht

Dass er flog, der Vogel, war Grund Noch dass er schwamm im salzigen Nass Der Fisch

Als er verschwand dem Fleische zulieb.

Es ist alles gleich

Denn mir ist übel, glaubt

Mir: mir ist übel.

Ich kann nicht tun mehr

Was gut mir und vorbestimmt

Und das, was Euch nichts

Ausmacht: dass der Regen

Von oben nach unten fällt

Das ist mir

Ganz unerträglich. Dass im Alphabet

nach $A$ B kommt und nichts

Sonst. Euch ists recht

Aber mir ists ganz ärmlich.

Fatzer, du musst eine Rechnung machen

Mit aller Weisheit und Erfahrung

Deines Alters, die

Nicht aufgeht.

[....
El aire de la batalla lleno de humo y fuego

De un dia de verano

$\mathrm{Ni}$ este Fatzer de aquel

Por lo tanto, las situaciones son

Las madres de los hombres.

Hay también otras cosas y otros caminos

$$
\text { Pero yo }
$$

No aconsejo elegirlos.

No es justo el juicio

Del hombre sobre el hombre

Como salidos de

Un inmenso estómago

Cuyos jugos derriten

Hueso y piel

En la mierda no se distingue

La manzana del pescado

Triste masa donde la vida humana

Saborea ante los ojos del mundo

Lo que atrapó para calmar

Su voraz apetito

Surgidos de aire y agua

No es

Ni porque vuele el pájaro

Ni porque nade en agua salada

$$
\text { Elpez }
$$

Razón suficiente para que el ansia de carne los extermine. Todo da igual

Tengo ganas de vomitar

Creedme: Tengo ganas de vomitar.

Ya no puedo hacer

Lo que me conviene y me está predestinado

$Y$ lo que a nadie

Importa: que la lluvia

Caiga de arriba abajo

Me resulta

Insoportable.

En el alfabeto

Después de la $A$ viene la $B$ y nada

Más. Estaréis de acuerdo

Pero yo me siento un pobre infeliz.

Fatzer, haz

Cuentas

Con la sabiduria y experiencia

Que corresponde a tu edad, que esto

No cuadra.

(...)
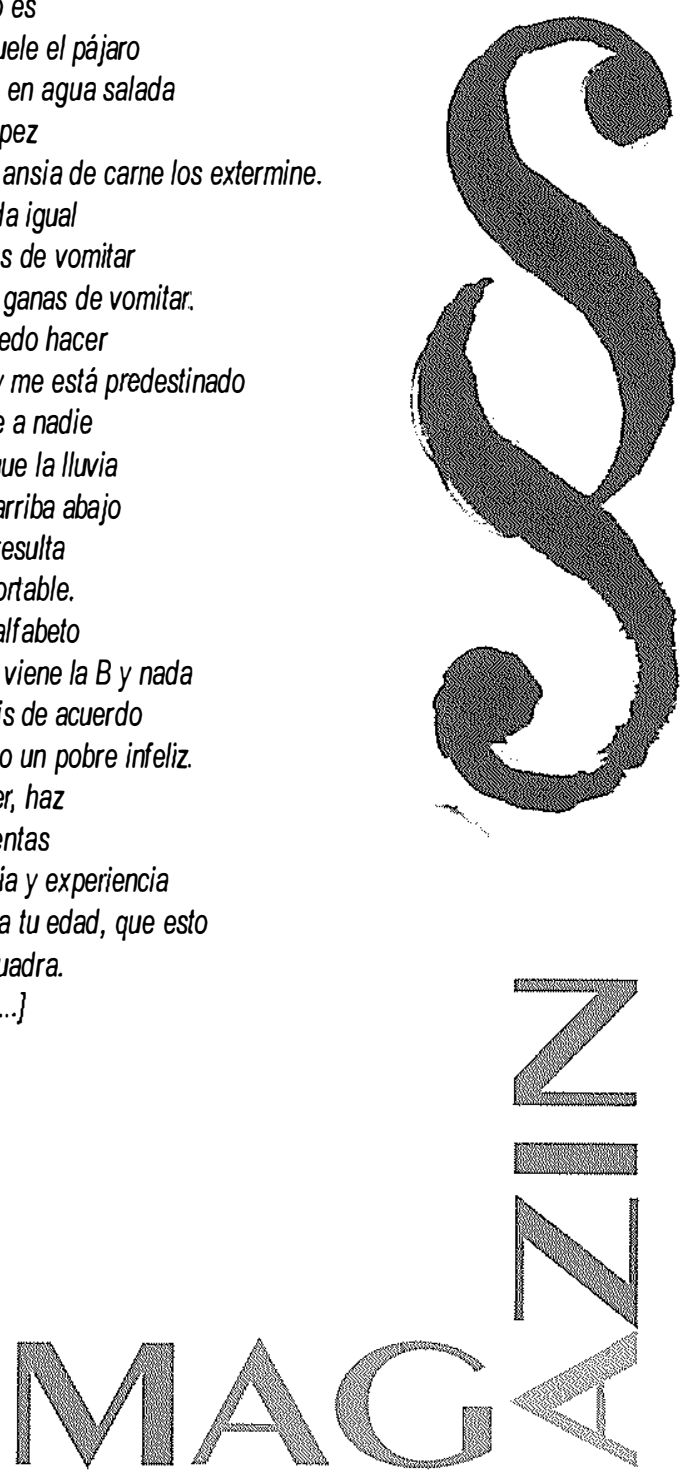
CHOR

Verlass deinen Posten.

Die Siege sind effochten. Die Niederlagen sind

Erfochten:

Verlass jetzt deinen Posten.

Tauche wieder unter in der Tiefe, Sieger.

der Jubel dringt dorthin, wo das Gefecht war.

Sei nicht mehr dort.

Erwarte das Geschrei der Niederlage dort, wo es am lautesten ist:

In der Tiefe.

Verlass den alten Posten.

Ziehe deine Stimme ein, Redner:

Dein Name wird ausgewischt auf den Tafeln. Deine Befehle

Werden nicht ausgeführt. Erlaube,

$\mathrm{Da}$ ( neue Namen auf der Tafel erscheinen

und

Neue Befehle befolgt werden.

(Du, der nicht mehr befiehlt

Fordere nicht zum Ungehorsam auf!)

Verlass den alten Posten

Du hast nicht ausgereicht.

Du bist nicht fertig

Jetzt hast du die Erfahrung und reichst aus

Jetzt kannst du beginnen:

Verlass den Posten.

Du, der die Ämter beherrscht hat

Heize deinen Ofen.

Du, der nicht Zeit hatte zu essen

Kochdir Suppe.

$D u$, über den viel geschrieben ist

Studiere das ABC.

Beginne sofort damit:

Beziehe den neuen Posten.

Der Geschlagene entrinnt nicht

Der Weisheit.

Halte dich fest und sinke! Fürchte dich! Sinke doch!

Auf dem Grunde

Enwartet dich die Lehre.

Zu viel Gefragter

Werde teilhaffig des unschätzbaren

Unterrichts der Masse:

\section{CORO}

Deja tu puesto

Las victorias están contadas. Las derrotas están

Contadas:

Deja tu puesto.

Desaparece en las profundidades y vence.

El júbilo llega hasta el campo de batalla.

Vete de alli.

Soporta el griterio de la derrota, donde más retumba:

En las profundidades.

Deja el viejo puesto.

Retrae tu voz, orador.

Tu nombre se ha borrado de las pizarras. Tus órdenes

No se ejecutan. Deja

Que se escriban nuevos nombres en la pizarra y

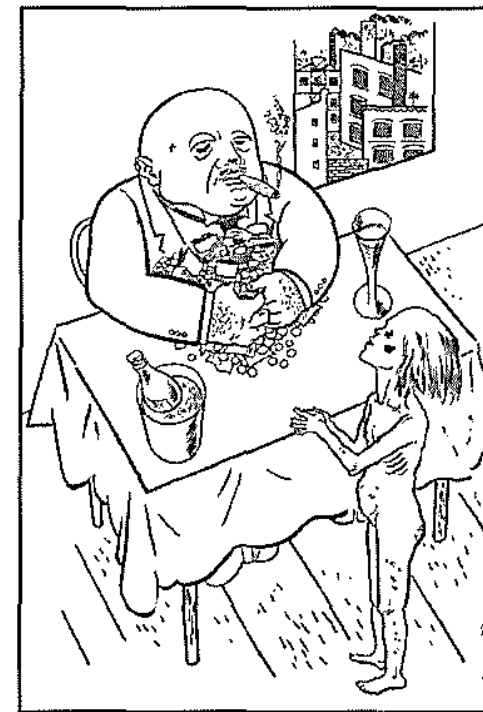

Litografia de Geroge Grosz para "Los Bandidos" de Schiller

Aprende el ABC.

Comienza ya:
Se sigan nuevas órdenes.

(Tú, que ya no mandas

¡No incites a la desobediencia!)

Deja el viejo puesto.

No es suficiente aún

Todavia no has acabado

Ahora tienes experiencia y eso es suficien-

te

Puedes empezar de nuevo:

Deja el puesto.

Si tenias cargos

Quédate en casa.

Si no tenias tiempo para comer

Prepárate un guiso.

Si escribian mucho sobre ti

Ocupa el nuevo puesto.

El derrotado no escapa

A la sabiduria.

¡Agárrate y húndete!; Ten miedo! jHúndete de una vez!

Hasta el fondo

Te espera la lección.

Tú que enseñaste a todos

Aprende con las inestimables

Enseñanzas de la masa:

Ocupa el nuevo puesto. 
Beziehe den neuen Posten.

Der Tisch ist fertig, Tischler,

Gestatte, dass wir ihn wegnehmen.

Hoble jetzt nicht weiter daran herum

Höre auf mit dem Anstreichen

Rede nicht davon gut noch übel:

So wie er ist, nehmen wir ihn.

Wir brauchen ihn.

Gib ihn heraus.

\section{Du bist fertig, Staatsmann}

Der Staat ist nicht fertig.

Gestatte, dass wir ihn verändern

Nach den Bedingungen unseres Lebens.

Gestatte, dass wir Staatsmänner sind, Staatsmann.

Unter deinen Gesetzen steht dein Name.

Vergiss den Namen

Achte deine Gesetze, Gesetzgeber:

Lass dir die Ordnung gefallen, Ordner.

Der Staat braucht dich nicht mehr

Gibihn heraus.

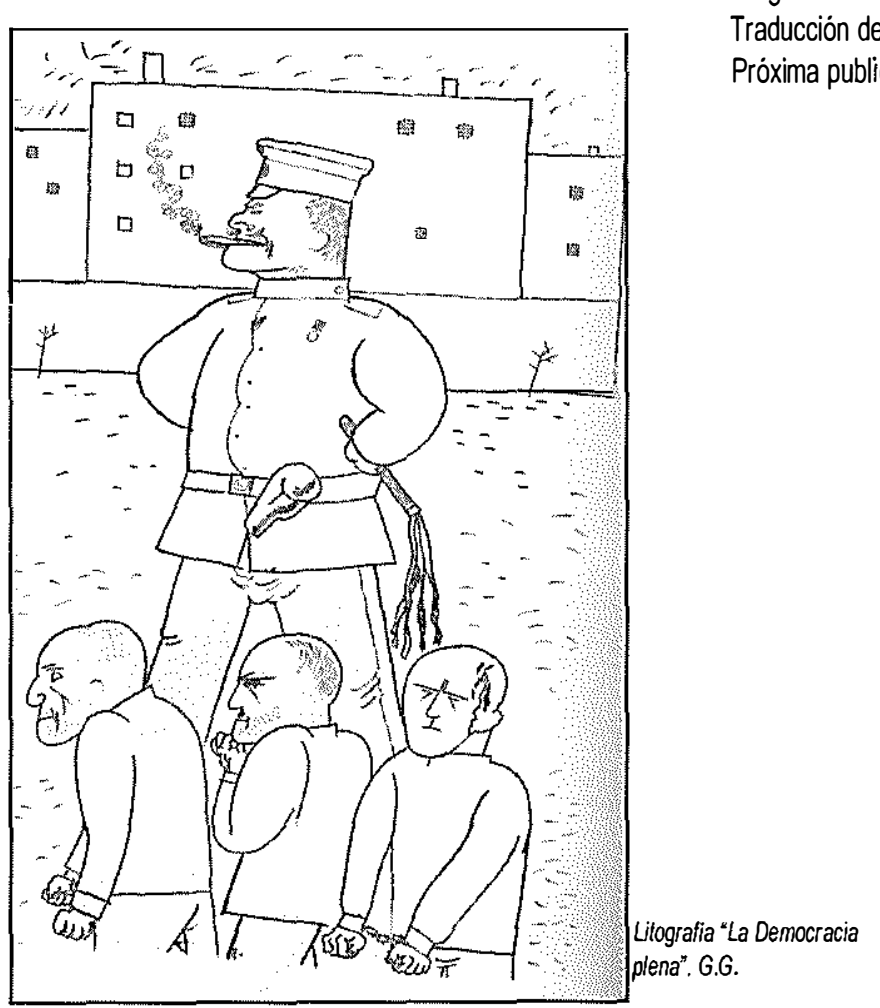

La mesa está acabada, carpintero.

Permitenos llevárnosla.

No la cepilles más

Deja de pintarla

No hables ni bien ni mal de ella:

Nos la llevamos, asi como está.

La necesitamos.

Entrégala.

Estás acabado, estadista.

Y el Estado aún no está acabado.

Permitenos cambiarlo

De acuerdo a nuestras circunstancias.

Estadista, permitenos ser estadistas.

Debajo de tus leyes está tu nombre.

Olvida el nombre

Respeta tus leyes, legislador.

Soporta el orden, ordenador.

El Estado ya no te necesita

Entrégalo.

Fragmentos de "La caida del egoista Johann Fatzer" Traducción de Hiltrud Hengst y Pedro Álvarez-Ossorio. Próxima publicación por la Diputación de Sevilla. 